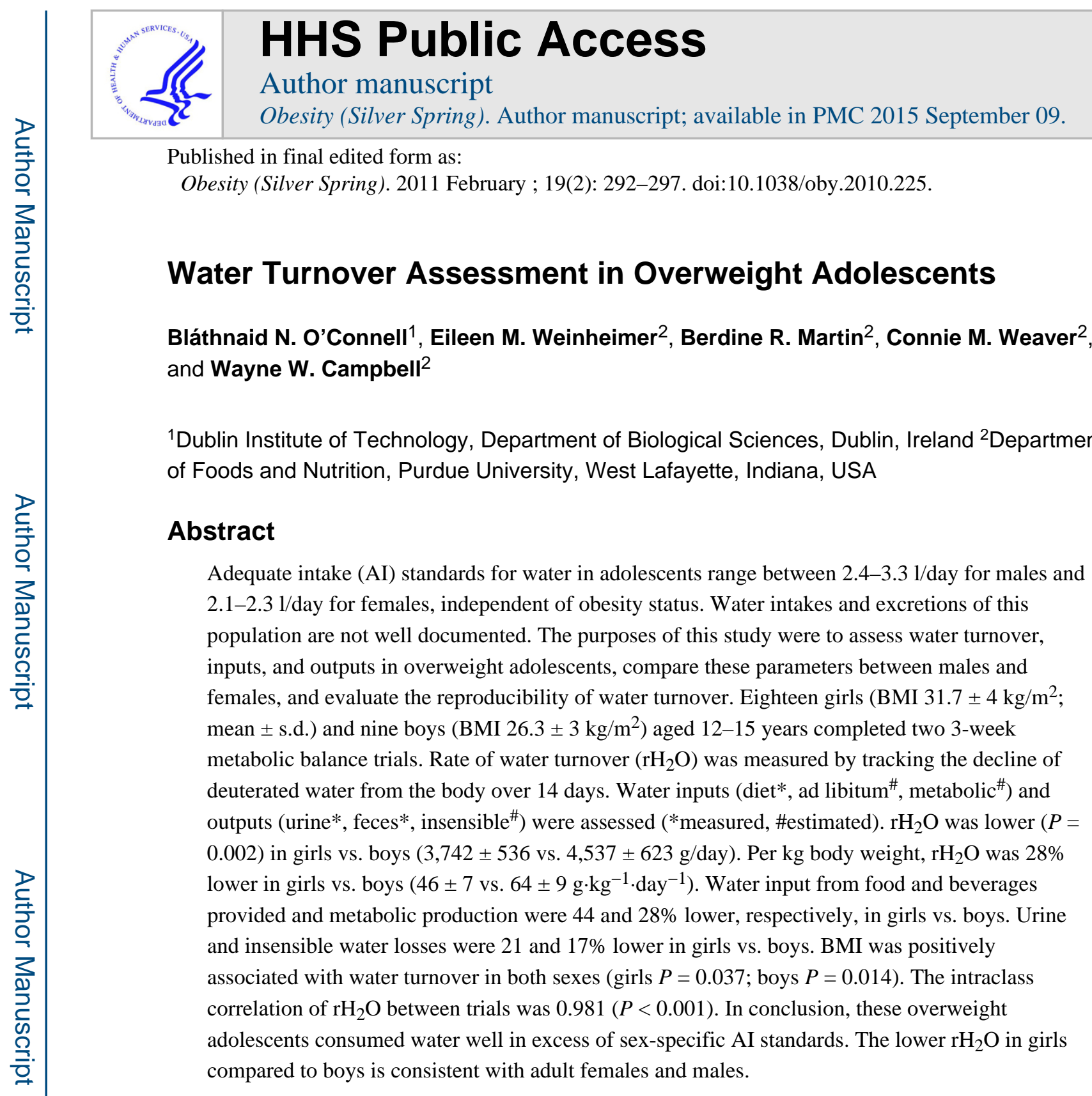

\title{
INTRODUCTION
}

Water is the largest constituent in the human body (1). Total body water (TBW) constitutes $\sim 55 \%$ body weight in adolescents (2) and can vary depending on age, sex, and percentage body fat (3). Water turnover is defined as the input and output of water over a given period of time (4) and reflects body water homeostasis (3). Water input consists of water from beverages and food, ad libitum intake, and metabolic water production (1) and water output consists of urinary, fecal, sweat, and insensible (nonsweat transcutaneous and respiratory) losses (1). Limited information exists regarding water turnover in obese individuals, especially adolescents. Presently, only one study has evaluated water turnover in normal

Correspondence: Wayne W. Campbell (campbellw@purdue.edu).

DISCLOSURE

The authors declared no conflict of interest. 
weight children (25th-75th percentile); the researchers reported a $40 \%$ decrease in water turnover from $160 \mathrm{ml} \cdot \mathrm{kg}^{-1} \cdot \mathrm{day}^{-1}$ at 6 weeks of age to $97 \mathrm{ml} \cdot \mathrm{kg}^{-1} \cdot \mathrm{day}^{-1}$ at 1 year (5). From years 1 to 15 water turnover continued to decrease, but at a slower rate, ending with a mean daily rate of water turnover of $46 \mathrm{ml} \cdot \mathrm{kg}^{-1} \cdot \mathrm{day}^{-1}$ in $10-12$-year olds and $40 \mathrm{ml} \cdot \mathrm{kg}^{-1} \cdot \mathrm{day}^{-1}$ in 13-15-year olds (5). The influence of sex on water turnover was not described. Raman et al. (6) reported a higher water turnover rate in adult males of $3.61 /$ day compared to $3.01 /$ day in adult females. To our knowledge, no studies have documented water turnover in overweight children to estimate the association between water turnover and obesity, or have evaluated differences between male and female adolescents.

Water turnover studies have been carried out to evaluate water needs (7). Adequate intake (AI) standards in the United States for water in adolescents range between 2.4-3.3 1/day for males and 2.1-2.31/day for females, independent of obesity status (1). AIs are based on median intakes of total water from US survey data (8), and do not take into account water turnover studies. Water needs are based upon metabolic rate, body surface area, and body weight $(9,10)$ - parameters which are higher in obese individuals compared to nonobese individuals $(11,12)$. Therefore, obese individuals may have higher water needs than nonobese individuals.

The results presented in this project were obtained as a secondary objective from a study that assessed the effect of calcium intake on fat balance predictors in overweight adolescents. Because no evidence suggests that calcium supplementation influences water metabolism, the use of doubly labeled water with the provision of strict dietary control, and complete urine and stool collections gave us the opportunity to assess water turnover, inputs, and outputs in this population. In addition, duplicate trials provided us with the opportunity to assess reproducibility of the results. Thus, the purposes of this study were to assess water turnover, inputs, and outputs in overweight adolescents, compare these parameters between males and females, and evaluate the reproducibility of water turnover. We hypothesized that water turnover would be higher in boys vs. girls, and related to body composition.

\section{METHODS AND PROCEDURES}

Overweight adolescents (18 girls and 9 boys) were recruited to participate in two 3-week metabolic balance studies, which were separated by a 3-week washout period. All subjects were apparently healthy adolescents who were "at risk" for being overweight or overweight (>85th percentile BMI for age). During each trial, all subjects lived in a supervised environment (residence hall on Purdue University campus) and consumed an energycontrolled diet. They resumed their habitual diet and physical activity patterns upon their return home for the washout period. Subjects received a monetary stipend for participation. The study protocol was approved by the Purdue Institutional Review Board and all subjects and their guardians provided written informed consent before participation.

\section{Dietary intake and physical activity during the balance studies}

Dietary intake was controlled during each 3-week study; three meals and two snacks were prepared by staff, and subjects consumed these under supervision. A 4-day cycle menu was used. All foods and beverages were prepared using deionized water and then weighed to the 
nearest $0.1 \mathrm{~g}$. The macronutrient content of the diet was $15 \%$ energy from protein, $55 \%$ energy from carbohydrate, and 30\% energy from fat. Each subjects' energy requirement was estimated using formulas in the Dietary Reference Intakes (13), with a physical activity level of $\geq 1.6$ but $<1.9$ times their resting energy expenditure. Physical activity levels were matched between trials.

Basal diets of five different energy intake levels were prepared daily. If a subject's energy requirement exceeded that of the basal diet, additional energy was provided by cookies, with a similar macronutrient composition to that of the basal diet, to bring them as near as possible to their estimated energy requirement.

Participants received diets containing either $650 \mathrm{mg}$ or $1,300 \mathrm{mg}$ calcium/ day including a basal diet of $650 \mathrm{mg}$ and two smoothies per day containing a total of either 0 (control) or $650 \mathrm{mg}$ calcium as calcium carbonate or dairy calcium.

\section{Body composition assessment}

Dual-energy X-ray absorptiometry (Prodigy; GE Health Systems- Lunar, Madison, WI) was used to determine fat mass, lean body mass, and percentage of body fat. Body surface area was estimated using the formula from DuBois and DuBois (14).

\section{Doubly labeled water protocol}

Doubly labeled water was administered on day 7 of each trial. Subjects were weighed in the morning and baseline urine was collected. An oral dose of doubly labeled water was administered at $8 \mathrm{am}$, and contained $\sim 1.8 \mathrm{~g} / \mathrm{kg}$ TBW of $\approx 10 \mathrm{AP}$ (atom \%) $\mathrm{H}_{2}{ }^{18} \mathrm{O}$ and 0.14 $\mathrm{g} / \mathrm{kg}$ total water $99.9 \mathrm{AP} \mathrm{D}_{2} \mathrm{O}$ (Cambridge Isotope Laboratory, Andover, MA). Subjects consumed preweighed portions of deionized water over $4-6 \mathrm{~h}$, to maintain urine production. Postdose spot urine samples $(4.5 \mathrm{ml})$ were collected at 2,4 , and $6 \mathrm{~h}$, and complete urine samples were maintained for balance studies. All urine samples were frozen for later analysis.

During the 14 days of water turnover assessment in trials 1 and 2, the average outside temperature was $69 \pm 2$ and $69 \pm 1{ }^{\circ} \mathrm{F}$, respectively, and the average humidity was $81 \pm 4 \%$ and $81 \pm 4 \%$, respectively.

\section{Isotopic analysis}

Baseline, $6 \mathrm{~h}$, day 7 , and day 14 urine samples were analyzed for ${ }^{2} \mathrm{H}$ (deuterium) and ${ }^{18} \mathrm{O}$ abundances. Isotopic analysis was carried out as described elsewhere $(6,15)$ using isotope ratio mass spectrometry (Delta Plus and Delta V; Thermo Scientific, Waltham, MA).

\section{Calculations}

Total body water-The isotope dilution space $(\mathrm{N})$ of ${ }^{2} \mathrm{H}$ and ${ }^{18} \mathrm{O}$ were calculated according to previous methods (16)

$$
N(\mathrm{~kg})=(W A / 1,000 a)\left(\delta_{a}-\delta_{t}\right) /\left(\delta_{s}-\delta_{p}\right)
$$


where $W$ is water (g) used to dilute the dose water; $A$ is the dose water (g) administered to the subject, and $a$ is the dose water (g) used in the dilution; $\delta_{a}$ is the isotopic abundance of the diluted dose water; $\delta_{t}$ is the isotopic abundance of tap water that is used in the dilution; $\delta_{s}$ is the isotopic abundance of postdose specimen; and $\delta_{p}$ represents the isotopic abundance of the predose specimen. These isotopic abundances are measured in permil units $[\delta \% o=$ $\left(R / R_{S}-1\right) 1,000$, where $R$ represents the ratio of heavy to light hydrogen isotope in the sample $(R)$ and standard $\left(R_{S}\right)$ ]. The ratio of ${ }^{2} \mathrm{H}$ to ${ }^{18} \mathrm{O}$ dilution spaces averages $1.034 \pm$ 0.018 .

TBW was calculated as an average of the ${ }^{2} \mathrm{H}$ dilution space $\left(N_{d}\right)$ and the ${ }^{18} \mathrm{O}$ dilution space $\left(N_{o}\right)$ after correcting for in vivo isotopic exchange, using the equation (17):

$$
\operatorname{TBW}(\mathrm{kg})=\left(N_{\mathrm{o}} / 1.007+N_{\mathrm{d}} / 1.042\right) / 2
$$

Water turnover-Water turnover ( $\mathrm{kg} /$ day) in the body was calculated from the ${ }^{2} \mathrm{H}$ dilution space and elimination rate (18)

$$
\mathrm{rH}_{2} \mathrm{O}=N_{d} \times k_{d}
$$

and

$$
k_{d}=\left[\ln \left(c_{f}-c_{i}\right)\right] /\left(t_{f}-t_{i}\right)
$$

where $N_{d}$ is the dilution space measured using ${ }^{2} \mathrm{H}, k_{d}$ is the fractional turnover rate of ${ }^{2} \mathrm{H}$ in the body water after equilibration, $c_{f}$ is the final enrichment of ${ }^{2} \mathrm{H}$ in the urine, $c_{i}$ is the initial enrichment of ${ }^{2} \mathrm{H}$ in the urine, $t_{f}$ is the final time point, and $t_{i}$ is the initial time point.

In calculating water turnover, a balance between water influx and efflux was assumed.

\section{Water inputs}

Water intake from foods and beverages: This was calculated as the sum of water from beverages and the basal diet. Meal composites were prepared daily, and were frozen, thawed at a later date, homogenized and freeze dried. The water content was the difference between prefreeze drying and postfreeze drying weight. The amount of water present in the smoothies was assessed using proximate analysis.

Ad libitum water intake: This was calculated as the difference between water turnover and the sum of metabolic water production and dietary water consumed.

Metabolic water: Metabolic water production was calculated from the average macronutrient content of the diet of healthy Americans according to this equation:

Metabolic water $(1 /$ day $)=\operatorname{TEE} \times\left(1 / 10^{5}\right)[(\%$ protein $\times 0.103)+(\%$ fat $\times 0.119)+(\%$ carbohydrate $\times 0.15)]$, 
where TEE is $\mathrm{kcal} / \mathrm{day}$ and $\%$ protein, $\%$ fat, and $\%$ carbohydrate are assumed as 15,30 , and $55 \%$, respectively. The amount of water produced per kcal of substrate oxidized as protein, fat, and carbohydrate is $0.103,0.119$, and 0.15 , respectively.

Water outputs Urinary losses: Urine was collected in acid wash containers and pooled in 24-h collections for the duration of the study period; the final collection was the first sample of the following morning. The urine was acidified using concentrated hydrochloric acid (1\% by volume) and aliquots were frozen at $-10{ }^{\circ} \mathrm{C}$. The urine samples were combined in a weighted manner and pooled by each trial of the metabolic study. Urinary water losses were then averaged from fourteen 24-h urine collections in each trial.

Fecal losses: Total fecal slurry samples were measured in preweighed containers and frozen. Completeness of fecal collections was assessed by measuring polyethylene glycol (polyethylene glycol, E3350; Dow Chemical, Midland, MI) in the stools. One gram of polyethylene glycol (in capsules) was given to the subjects with each meal daily to total $3 \mathrm{~g}$ daily. Samples were pooled for $24 \mathrm{~h}$, diluted with concentrated hydrochloric acid and ultrahigh-purity water, and then homogenized with a stomacher (Laboratory-Blender 3500 ; Tekmar, Cincinnati, OH). The samples were freeze dried (VirTis; SP Industries, Gardiner, $\mathrm{NY}$ ) and pulverized and percent fecal solids was calculated. Fecal water losses were calculated as the difference between the total fecal slurry weight and the sum of the dry fecal weight, added water and acid.

Insensible water losses: Insensible water losses were calculated as the difference between water turnover and the sum of urinary and fecal water losses.

\section{Assessment of hydration status}

The specific gravity of each 24-h urine sample was measured using a digital refractometer (Model DFR301; MISCO, Cleveland, OH), to assess each subject's hydration status, and the results are reported as a 21-day mean for each trial. Clinical normalcy was based on a specific gravity between 1.006 and 1.020 (19).

\section{Statistical analysis}

Water turnover analyses were obtained as a secondary objective to a study designed to assess the effect of calcium intake on fat balance predictors, thus, power calculations to determine sample size were not conducted specifically for water turnover assessment. A two-way ANOVA was carried out to confirm that calcium intake did not influence water turnover. Because the treatment ( $650 \mathrm{mg}$ or $1,300 \mathrm{mg}$ calcium/day) did not statistically influence the results for the current investigation, the data on water turnover and the components of inputs and outputs from the low- and high-calcium trials were averaged (pooled) for each subject. Potential sex differences were analyzed using unpaired $t$-tests. Pearson correlations were used to assess the relationships between BMI, lean body mass, fat mass, and body surface area with water turnover. 
The inclusion of duplicate trials provided a unique opportunity to assess the reproducibility of the results during the two trials. The reproducibility of water turnover was calculated using the intraclass correlation coefficient.

Data are reported as mean \pm s.d. A $P$ value $<0.05$ was considered significant. Statistical analyses were performed using SPSS software (version 17.0, 2008; SPSS, Chicago, IL).

\section{RESULTS}

Subject characteristics are presented in Table 1. All the girls were classified as overweight (BMI >95th percentile). Six of the boys were classified as overweight, two were "at risk" of being overweight (BMI 85th-95th percentile), and one had a healthy body weight, but had been classified as overweight at the time of screening. There were no sex differences in age, height, and body surface area (Table 1). Girls had a higher body weight $(P=0.033)$, BMI ( $P$ $<0.0001)$, and tanner stage $(P=0.015)$ compared to boys. Lean body mass, as a percentage of total body weight, was higher in boys than girls $(P=0.025)$.

Figure 1 and Table 2 describe water turnover, inputs, and outputs in the subjects. Total water input was higher in boys than girls $(P=0.005)$. Water from food and beverages and estimated metabolic water production was 606 and $51 \mathrm{~g} /$ day higher, respectively, in boys than girls. Total water output was also higher in boys than girls $(P=0.005)$. Urine and insensible losses were 314 and $543 \mathrm{~g} /$ day higher in boys compared to girls, respectively. When expressed per kg body weight, water input and output were both higher in boys compared to girls $(P<0.0001$; Table 2$)$. This corresponds with higher water intakes of 10.4 $\mathrm{g} \cdot \mathrm{kg}^{-1} \cdot \mathrm{day}^{-1}$ from food and beverages and $1.5 \mathrm{~g} \cdot \mathrm{kg}^{-1} \cdot \mathrm{d}^{-1}$ from metabolic production, and higher water outputs through urine, fecal, and insensible losses of 6.9, 0.3, and 12.5 $\mathrm{g} \cdot \mathrm{kg}^{-1} \cdot \mathrm{day}^{-1}$, respectively, in boys compared to girls. Ad libitum water intake was not different between boys and girls. When matched for BMI and tanner stage, water turnover was not greatly influenced and remained higher in boys compared to girls (data not shown).

Data in Table 3 are the Pearson correlation coefficients between water turnover and BMI, lean body mass, fat mass, and body surface area. BMI was positively associated with water turnover in both sexes (Figure 2). Neither lean body mass nor fat mass appeared to influence water turnover, except in girls. No association was found between body surface area and water turnover. The intraclass correlation of water turnover between trials was 0.981 ( $P<$ 0.0001; Figure 3). Hydration status was clinically normal (19) in all subjects, with the exception of one female subject who had a urine specific gravity of 1.022 .

\section{DISCUSSION}

\section{Water turnover and intakes}

The present study is the first to assess water turnover, inputs, and outputs in 12-15-year-old overweight adolescents. We report a lower water turnover rate of $46 \mathrm{ml} \cdot \mathrm{kg}^{-1} \cdot \mathrm{day}^{-1}$ in girls compared to $64 \mathrm{ml} \cdot \mathrm{kg}^{-1} \cdot \mathrm{day}^{-1}$ in boys, averaging a combined rate of $52 \mathrm{ml} \cdot \mathrm{kg}^{-1} \cdot \mathrm{day}^{-1}$. Previously, only one study has documented water turnover in adolescents (5). Fusch et al. (5) reported a water turnover rate of $46 \mathrm{ml} \cdot \mathrm{kg}^{-1} \cdot \mathrm{day}^{-1}$ in 9-12-year old and 40 
$\mathrm{ml} \cdot \mathrm{kg}^{-1} \cdot \mathrm{day}^{-1}$ in $13-15$-year-old children and adolescents of normal body weight. However, this study did not assess sex differences in water turnover. Not only is our research the first study to report water turnover in overweight adolescents, it is also the first to report sex differences in water turnover in this population.

The lower water turnover in girls vs. boys is consistent with data in adult females and males. Raman et al. (20) assessed water turnover, water inputs, and urine excretion in 458 noninstitutionalized adults, aged 40-79 years. The average rate of water turnover was 3.0 $1 /$ day $\left(42 \mathrm{ml} \cdot \mathrm{kg}^{-1} \cdot \mathrm{day}^{-1}\right)$ in adult females and $3.6 \mathrm{l} / \mathrm{day}\left(42 \mathrm{ml} \cdot \mathrm{kg}^{-1} \cdot \mathrm{day}^{-1}\right)$ in adult males, whereas our study showed adolescent females had a water turnover of $3.7 \mathrm{l} /$ day compared to $4.51 /$ day in adolescent males. The higher water turnover rates in male adolescents and adults are reflective of higher TBW content and higher water requirements.

Higher water intakes are typically seen in males compared to females $(21,22)$. Total water intakes were examined in 479 9-13-year-old boys and girls during repeated 24-h studies with measured diet and fluid intakes and urine collections. Boys reportedly had an intake of $1.9 \mathrm{l} /$ day compared to $1.7 \mathrm{l} /$ day in girls (21). Similarly, we report higher water intakes in overweight male adolescents ( $4.5 \mathrm{l} /$ day) compared to female adolescents ( 3.7 1/day). The higher water intake in the boys corresponds with higher water intakes from food and beverages (138 g/day) and metabolic production ( $51 \mathrm{~g} /$ day) compared to girls. This is not surprising as boys have higher energy requirements (13), thus consume more food and obtain more water from foods and metabolic production than girls (1). In this study, the repeated provision of energy- and macronutrient-defined menus maintained food and beverage water inputs, and kept metabolic water production constant. Therefore, the only component of water input that varied was ad libitum water consumption. There were no sex differences in ad libitum water consumption. These findings suggest that the higher water inputs in boys are mostly accounted by increased water from food and beverages and metabolic production.

\section{Reproducibility}

A unique advantage of this tightly controlled study design was that it provided the opportunity to assess the reproducibility of water turnover during the two metabolic balance trials. Figure 3 shows that the rates of water turnover for boys and girls are highly associated between trials 1 and 2 . This suggests that water turnover is a tightly controlled process in this population, and that ad libitum water intakes are comparable between trials, because this was the only component of water input that varied. Our findings extend the previous observations in younger and older men and women during repeated periods of controlled feeding $(23,24)$, and further support that the physiological drive to establish and maintain water homeostasis is strong and reproducible in adolescents and adults.

\section{Water intakes and obesity}

Previous research has shown that higher water intakes are associated with a higher BMI (22), and we would expect water turnover to be higher as BMI increases, which our results indicate (boys: $r=0.775, P=0.014$; girls: $r=0.495, P=0.037$ ). Presumably, water turnover rates increase with higher BMIs as subjects with higher BMIs have higher energy 
requirements (25), consume more food (26), and thus have increased water inputs from food and metabolic production (1). Consumption of dry, prandial food will also stimulate drinking (1) which may cause overweight adolescents to consume more ad libitum water. When we compare our results to findings in normal weight (25th-75th percentile) adolescents (5), BMI also appears to influence water turnover. We report a water turnover rate of $52 \mathrm{ml} \cdot \mathrm{kg}^{-1} \cdot \mathrm{day}^{-1}$ in 12-15-year-old overweight adolescents, whereas Fusch et al. (5) reported water turnover rates of $\sim 43 \mathrm{ml} \cdot \mathrm{kg}^{-1}$. $\mathrm{day}^{-1}$ in normal weight 9-15-year olds. Therefore, higher water inputs may result in higher water turnover rates in overweight adolescents compared to their lean counterparts. In addition, when we matched subjects for BMI, water turnover remained higher for boys (data not shown) which further supports that higher water inputs account for the higher water turnover in boys. Further studies are needed directly to elucidate these differences.

Higher water intakes have been associated with a decreased risk of obesity in the long term (27). Children who have the greatest hydration status reportedly have a higher total water intake, consume a lower energy density diet and less energy from fat, and produce less metabolic water compared to insufficiently hydrated children (27). All of the adolescents in our study had water intakes above the AIs and were well hydrated (within clinical normalcy) with the exception of one female adolescent (urine specific gravity 1.022). Overweight and obese persons have greater absolute lean body mass and body surface area compared to their lean counterparts, but we found no association between lean body mass or body surface area and water turnover (which matched water inputs). Our findings contrast with previous research that suggests higher water intakes are associated with a decrease in obesity in adolescents. However, our findings are limited in that we did not have a lean group comparison, and the trials were carried out in a controlled environment which may not reflect the normal eating and drinking habits of the subjects. Future studies that examine the relationship between water consumption, energy consumption, and obesity under free-living conditions are warranted.

\section{Water outputs}

Insensible losses, which consist of water lost by respiration and transdermal diffusion through the skin (28), are also affected by changes in the environment and physical activity levels (29). In an adult, insensible losses represent $\sim 30 \%$ of total water outputs, or $\sim 700$ $\mathrm{ml} /$ day at rest (30). When sweat is included in insensible losses this accounts for $35 \%$ of total water outputs ( $\sim 820 \mathrm{ml} /$ day) at rest (30). Insensible losses in adolescents are not well established. In this study, sweat losses were included within the estimation of insensible losses and account for $72 \%$ of total water output in boys and girls. The higher insensible losses reported in our subjects may be due to higher activity levels compared to those in other studies in children or different ambient temperatures. Temperature and humidity affect insensible losses (28); our study was conducted during the summer with an average outside temperature and humidity of $69 \pm 2{ }^{\circ} \mathrm{F}$ and $81 \pm 4 \%$, respectively. Studies show that overweight or obese individuals are under a greater strain while working or exercising in the heat compared to normal-weight individuals $(31,32)$. We did not directly measure sweat loss in these adolescents, but can postulate that any increase in physical activity in the adolescents may have resulted in increased sweat and respiratory losses. 
Als

The AI's for female adolescents are 2.11 /day for 9-13-year olds and 2.31 /day for 14-18year olds, and 2.4 1/day in 9-13-year olds and 3.31/day in 14-18-year olds for male adolescents (8). All of our subjects had water intakes in excess of the AI standards. This finding contrasts with results reported in adults in which the average water intake of 40-79year-old adults were below the AI of 3.7 and $2.7 \mathrm{l} /$ day for men and women, respectively, with the exception of women aged 40-49 years, whose average intake was 2.75 1/day (20). These data are also inconsistent with data from Fusch et al. (5), which stated fluid intakes in healthy German children and adolescents were $\sim 37.5 \mathrm{ml} \cdot \mathrm{kg}^{-1} \cdot \mathrm{day}^{-1}$ which is less than the recommended fluid intakes for that population $\left(50-85 \mathrm{ml} \cdot \mathrm{kg}^{-1} \cdot \mathrm{day}^{-1}\right)$. Nonetheless, our study suggests that overweight adolescents in the United States consume water in excess of current recommendations.

\section{Limitations and future directions}

The present study is limited to overweight and obese adolescents in a controlled environment. It is unknown if their water inputs and outputs would be similar in a freeliving environment. We would postulate that water turnover would be similar because overweight and obese adolescents will consume more food than their lean counterparts (13), thereby obtaining more water from food, producing more metabolic water and possibly stimulating fluid intake (1). In addition, this study was carried out during the summer limiting the data both seasonally and geographically. Future studies are needed directly comparing water metabolism in lean and overweight and obese adolescents to help elucidate the role of water intake, if any, in obesity. It is also important to note that our small sample size may have limited our ability to adequately evaluate the relationships between water turnover and body composition (lean body mass, fat mass, BMI, and body surface area) and maturation status (tanner stage).

This article is the first documentation of water turnover in overweight adolescents. Rates of water turnover were higher in boys compared to girls, which reflects increased energy requirements, and thus higher water intakes from food and beverages and metabolic production in boys. Overweight boys and girls appear to consume water well in excess of current AI recommendations and maintain euhydration.

\section{Acknowledgments}

This study was supported by NIH 1 R 01 DK066108; T32AG025671; National Dairy Council.

\section{REFERENCES}

1. Institute of Medicine. Dietary Reference Intakes for Water, Potassium, Sodium, Chloride and Sulfate. Washington, DC: The National Academies Press; 2004.

2. Wells JC, Fewtrell MS, Davies PS, et al. Prediction of total body water in infants and children. Arch Dis Child. 2005; 90:965-971. [PubMed: 16113134]

3. Shimamoto H, Komiya S. The turnover of body water as an indicator of health. J Physiol Anthropol Appl Human Sci. 2000; 19:207-212.

4. Kochevar, D. Principles of Acid-Base Balance: Fluid and Electrolyte Therapy. In: Adams, H., editor. Vetinary Pharmacology and Therapeutics. Ames: Blackwell Publishing; 2001. p. 504 
5. Fusch C, Hungerland E, Scharrer B, Moeller H. Water turnover of healthy children measured by deuterated water elimination. Eur J Pediatr. 1993; 152:110-114. [PubMed: 8383051]

6. Raman A, Schoeller DA, Subar AF, et al. Water turnover in 458 American adults 40-79 yr of age. Am J Physiol Renal Physiol. 2004; 286:F394-F401. [PubMed: 14600032]

7. Nagy KA, Costa DP. Water flux in animals: analysis of potential errors in the tritiated water method. Am J Physiol. 1980; 238:R454-R465. [PubMed: 6990797]

8. Campbell S. Hydration needs throughout the lifespan. J Am Coll Nutr. 2007; 26(5 Suppl):585S587S. [PubMed: 17921469]

9. National Research Council (US). Recommended Dietary Allowances. 10th edn.. Washington, DC: National Academy Press; 1989.

10. US Department of Agriculture. USDA Nutrient Database for Standard Reference, Release 15. Washington, DC: Department of Agriculture, Agricultural Research Service; 2002.

11. James WP, Davies HL, Bailes J, Dauncey MJ. Elevated metabolic rates in obesity. Lancet. 1978; 1:1122-1125. [PubMed: 77416]

12. Verbraecken J, Van de Heyning P, De Backer W, Van Gaal L. Body surface area in normalweight, overweight, and obese adults. A comparison study. Metab Clin Exp. 2006; 55:515-524. [PubMed: 16546483]

13. Food and Nutrition Board. Dietary Reference Intakes for Energy, Carbohydrate, Fiber Fat, Fatty Acids, Cholesterol, Protein and Amino Acids 2002. Washington, DC: The National Academies Press; 2005.

14. Du Bois D, Du Bois EF. A formula to estimate the approximate surface area if height and weight be known. 1916. Nutrition. 1989; 5:303-311. discussion 12-3. [PubMed: 2520314]

15. Singh R, Martin BR, Hickey Y, et al. Comparison of self-reported, measured, metabolizable energy intake with total energy expenditure in overweight teens. Am J Clin Nutr. 2009; 89:17441750. [PubMed: 19386746]

16. Cole TJ, Coward WA. Precision and accuracy of doubly labeled water energy expenditure by multipoint and two-point methods. Am J Physiol. 1992; 263:E965-E973. [PubMed: 1443129]

17. Racette SB, Schoeller DA, Luke AH, et al. Relative dilution spaces of $2 \mathrm{H}$ - and $18 \mathrm{O}$-labeled water in humans. Am J Physiol. 1994; 267:E585-E590. [PubMed: 7943308]

18. Fjeld CR, Brown KH, Schoeller DA. Validation of the deuterium oxide method for measuring average daily milk intake in infants. Am J Clin Nutr. 1988; 48:671-679. [PubMed: 2843027]

19. Popowski LA, Oppliger RA, Patrick Lambert G, et al. Blood and urinary measures of hydration status during progressive acute dehydration. Med Sci Sports Exerc. 2001; 33:747-753. [PubMed: 11323543]

20. Raman A, Schoeller D, Subar A, et al. Water turnover in 458 American adults $40-79 \mathrm{yr}$ of age. Am J Physiol Renal Physiol. 2004; 286:F394-F401. [PubMed: 14600032]

21. Sichert-Hellert W, Kersting M, Manz F. Fifteen year trends in water intake in German children and adolescents: results of the DONALD Study. Dortmund Nutritional and Anthropometric Longitudinally Designed Study. Acta Paediatr. 2001; 90:732-737. [PubMed: 11519974]

22. Kant AK, Graubard BI, Atchison EA. Intakes of plain water, moisture in foods and beverages, and total water in the adult US population-nutritional, meal pattern, and body weight correlates: National Health and Nutrition Examination Surveys 1999-2006. Am J Clin Nutr. 2009; 90:655663. [PubMed: 19640962]

23. Bossingham MJ, Carnell NS, Campbell WW. Water balance, hydration status, and fat-free mass hydration in younger and older adults. Am J Clin Nutr. 2005; 81:1342-1350. [PubMed: 15941885]

24. Weinheimer EM, Martin BR, Weaver CM, Welch JM, Campbell WW. The effect of exercise on water balance in premenopausal physically active women. J Am Diet Assoc. 2008; 108:16621667. [PubMed: 18926131]

25. United Nations University, World Health Organization, and Food and Agriculture Organization of the United Nations. Human energy requirements: report of a joint FAO/WHO/UNU Expert Consultation, Rome. 2001 Oct 17-24.

26. Lichtman SW, Pisarska K, Berman ER, et al. Discrepancy between self-reported and actual caloric intake and exercise in obese subjects. N Engl J Med. 1992; 327:1893-1898. [PubMed: 1454084] 
27. Stahl A, Kroke A, Bolzenius K, Manz F. Relation between hydration status in children and their dietary profile - results from the DONALD study. Eur J Clin Nutr. 2007; 61:1386-1392. [PubMed: 17311062]

28. Grandjean AC, Reimers KJ, Buyckx ME. Hydration: issues for the $21^{\text {st }}$ century. Nutr Rev. 2003; 61:261-271. [PubMed: 13677588]

29. Newburgh L, Johnston M. The insensible loss of water. Physiol Rev. 1942; 22:1-18.

30. Wilmore, J.; Costill, D. Physiology of Sports and Exercise. Champaign, IL: Human Kinetics; 1994.

31. Bar-Or O, Lundegren HM, Buskirk ER. Heat tolerance of exercising obese and lean women. J Appl Physiol. 1969; 26:403-409. [PubMed: 5775324]

32. Haymes EM, Buskirk ER, Hodgson JL, Lundegren HM, Nicholas WC. Heat tolerance of exercising lean and heavy prepubertal girls. J Appl Physiol. 1974; 36:566-571. [PubMed: 4826320] 


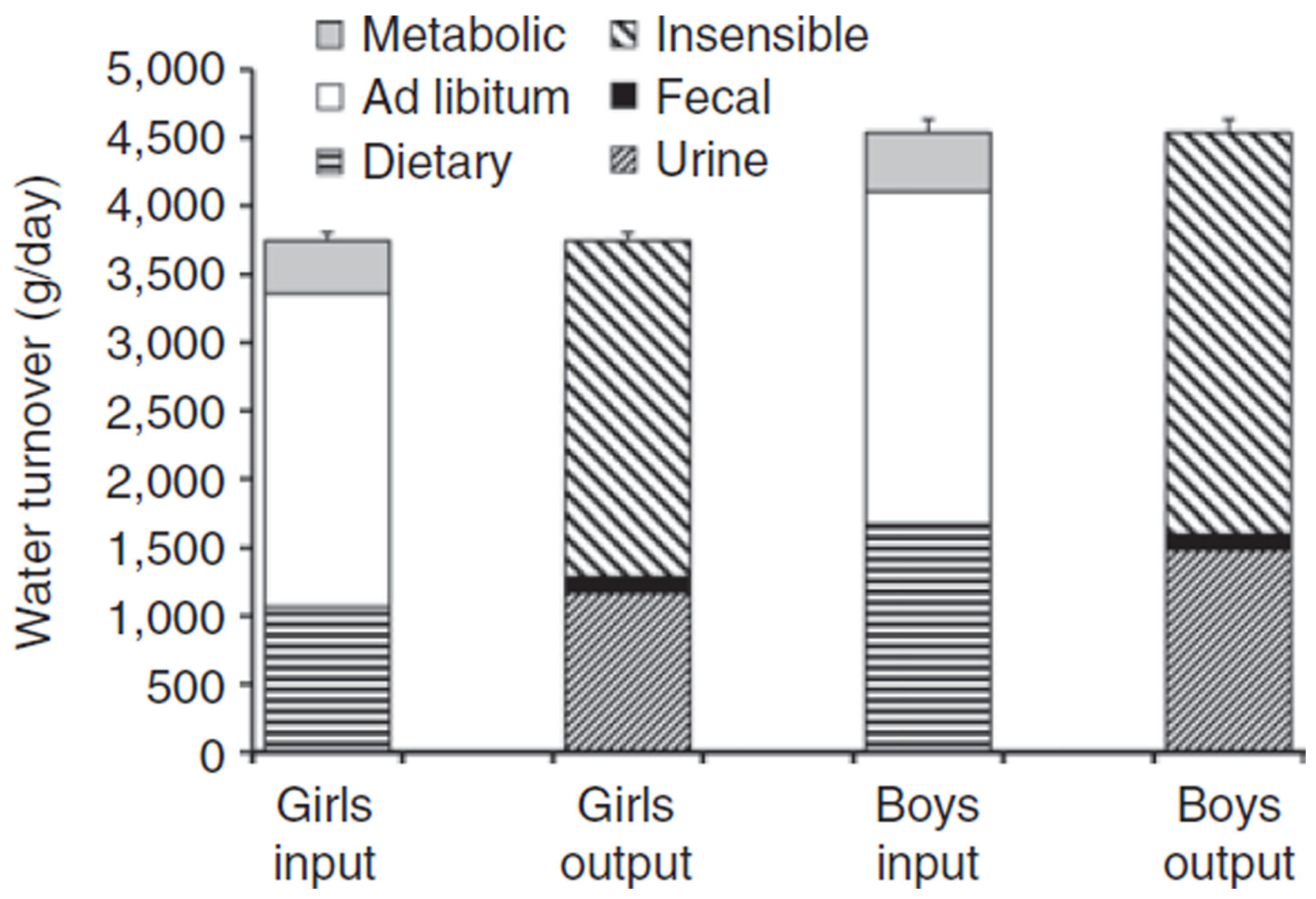

Figure 1.

Average water turnover, inputs, and outputs from the two trials in adolescent boys and girls. Ad libitum water intakes and fecal water losses were not different between boys and girls ( $P$ $>0.05$ ). 


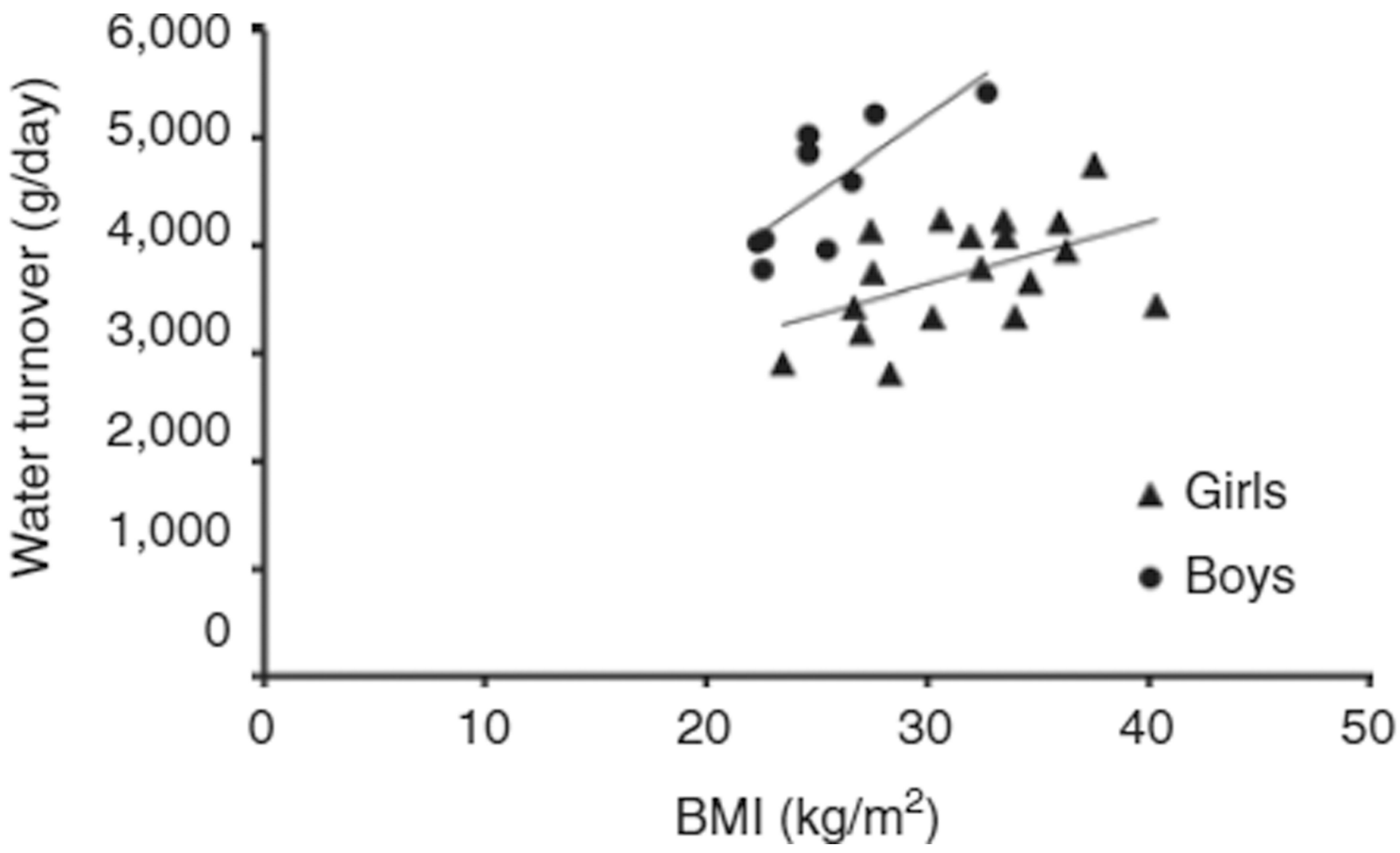

Figure 2.

Correlation between BMI and average water turnover from the two trials for boys and girls. BMI was associated with water turnover for boys $(r=0.775 ; P=0.014)$ and girls $(r=0.495$; $P=0.037)$. 


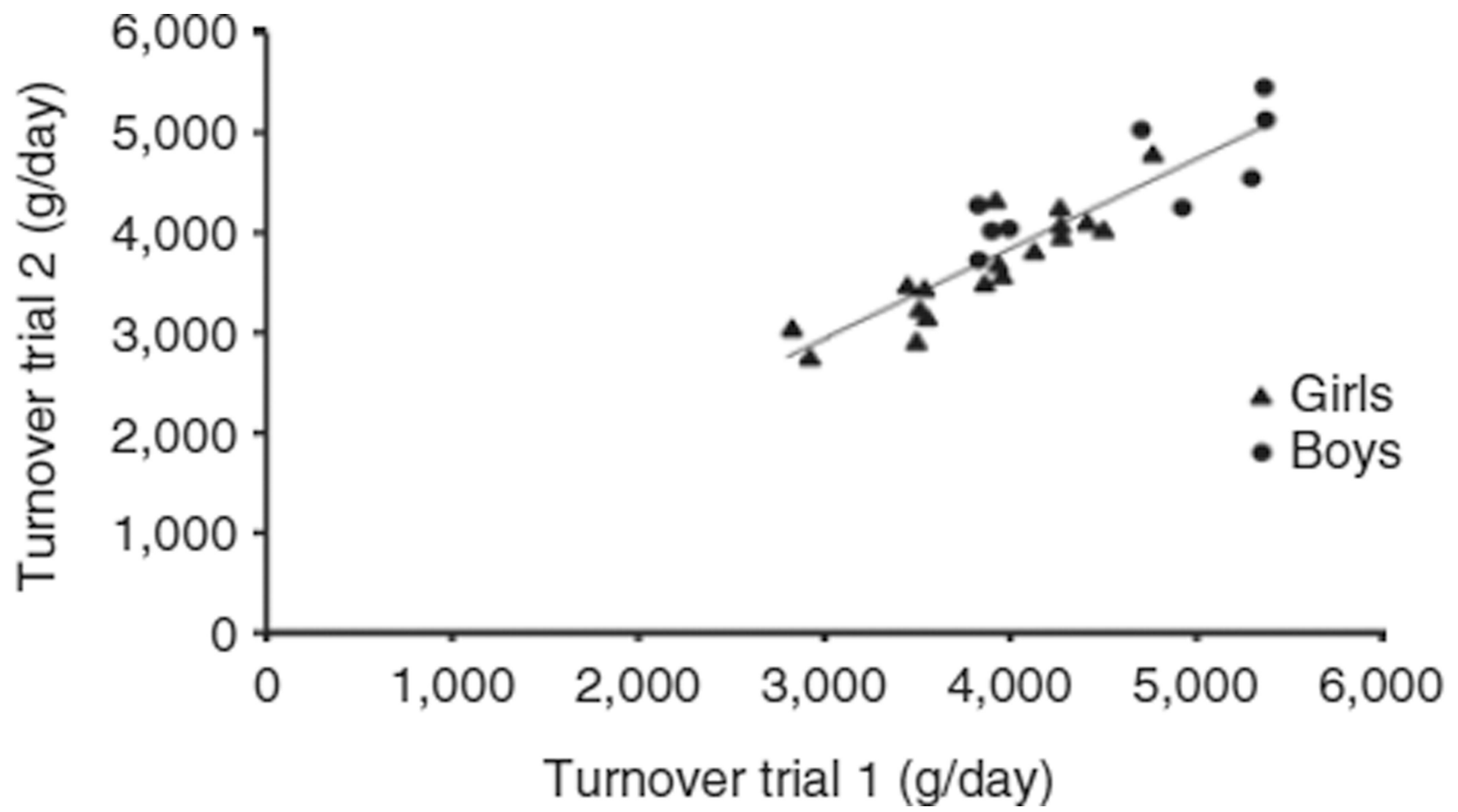

Figure 3.

Combined average water turnover during trial 1 vs. trial 2 . The intraclass correlation between trials was $0.981(P<0.001)$. 


\section{Table 1}

Subject characteristics

\begin{tabular}{lcc}
\hline & Boys & Girls \\
\hline Age (years) & $14 \pm 1$ & $13 \pm 1$ \\
Weight $(\mathrm{kg})$ & $71 \pm 11^{a}$ & $82 \pm 13$ \\
Height $(\mathrm{cm})$ & $167 \pm 8$ & $161 \pm 5$ \\
BMI $\left(\mathrm{kg} / \mathrm{m}^{2}\right)$ & $26 \pm 3^{a}$ & $32 \pm 4$ \\
Percent body fat & $37 \pm 10^{a}$ & $45 \pm 5$ \\
Fat mass (kg) & $26 \pm 10^{a}$ & $38 \pm 10$ \\
Lean body mass $(\mathrm{kg})$ & $44 \pm 6$ & $45 \pm 6$ \\
Lean body mass $(\% \mathrm{BW})$ & $63 \pm 3^{a}$ & $55 \pm 1$ \\
Body surface area (m²) & $1.75 \pm 0.16$ & $1.86 \pm 0.15$ \\
Tanner stage $b$ & $3.6 \pm 1.2^{a}$ & $4.6 \pm 0.8$ \\
\hline Data expressed as mean \pm s.d. & \\
${ }_{\text {Significantly different between boys and girls }(P<0.05) .}$ \\
$b_{\text {Tanner stage is based on a scale of } 1-5 .}$
\end{tabular}


Table 2

Water turnover, inputs, and outputs in overweight adolescents

\begin{tabular}{|c|c|c|c|c|}
\hline & \multicolumn{2}{|c|}{ Boys } & \multicolumn{2}{|c|}{ Girls } \\
\hline & g/day & $\mathrm{g} \cdot \mathrm{kg}^{-1} \cdot \mathrm{day}^{-1}$ & g/day & $\mathrm{g} \cdot \mathrm{kg}^{-1} \cdot \mathrm{day}^{-1}$ \\
\hline Water turnover & $4,537 \pm 605^{a}$ & $64.3 \pm 9.45^{a}$ & $3,742 \pm 517$ & $46.1 \pm 6.72$ \\
\hline \multicolumn{5}{|l|}{ Water input } \\
\hline Ad libitum & $2,431 \pm 631$ & $34.6 \pm 9.63$ & $2,293 \pm 490$ & $28.2 \pm 5.72$ \\
\hline Food and beverages & $1,673 \pm 239^{a}$ & $23.6 \pm 2.40^{a}$ & $1,067 \pm 82$ & $13.2 \pm 1.94$ \\
\hline Metabolic production & $433 \pm 28^{a}$ & $6.2 \pm 0.72^{a}$ & $382 \pm 41$ & $4.7 \pm 0.66$ \\
\hline Total & $4,537 \pm 605^{a}$ & $64.3 \pm 9.45^{a}$ & $3,742 \pm 517$ & $46.1 \pm 6.72$ \\
\hline \multicolumn{5}{|l|}{ Water output } \\
\hline Urine & $1,130 \pm 193^{a}$ & $16.4 \pm 4.71^{a}$ & $924 \pm 241$ & $11.6 \pm 3.85$ \\
\hline Fecal & $118 \pm 36$ & $1.7 \pm 0.45$ & $118 \pm 32$ & $1.4 \pm 0.33$ \\
\hline Insensible & $3,289 \pm 588^{a}$ & $46.3 \pm 6.29^{a}$ & $2,700 \pm 499$ & $33.0 \pm 4.93$ \\
\hline Total & $4,537 \pm 605^{a}$ & $64.3 \pm 9.45^{a}$ & $3,742 \pm 517$ & $46.1 \pm 6.72$ \\
\hline
\end{tabular}

Data expressed as mean \pm s.d.

${ }^{a}$ Significantly different between boys and girls $(P<0.05)$. 


\section{Table 3}

Associations between water turnover and lean body mass, fat mass, BMI, and body surface area for boys and girls combined and separate

\begin{tabular}{lcc}
\hline & $\begin{array}{c}\text { Pearson } \\
\text { correlation }(\boldsymbol{r})\end{array}$ & $\boldsymbol{P}$ value \\
\hline Lean body mass $(\mathrm{kg})$ & 0.314 & 0.111 \\
All & 0.385 & 0.307 \\
Boys & 0.500 & 0.034 \\
Girls & & \\
Fat mass $(\mathrm{kg})$ & 0.108 & 0.590 \\
All & 0.534 & 0.139 \\
Boys & 0.596 & 0.009 \\
Girls & & \\
BMI $\left(\mathrm{kg} / \mathrm{m}^{2}\right)$ & 0.028 & 0.888 \\
All & 0.831 & 0.005 \\
Boys & 0.495 & 0.037 \\
Girls & & \\
Body surface area $\left(\mathrm{cm}^{2}\right)$ & & \\
All & 0.081 & 0.688 \\
Boys & 0.270 & 0.482 \\
Girls & 0.401 & 0.099 \\
\hline
\end{tabular}

